\title{
Pedagogical Design Capacity and Underlying Knowledge Base of Curriculum Materials Use of a Hong Kong English Teacher
}

\author{
Ivan Chong ${ }^{1}$ \\ ${ }^{1}$ English Language Team, Yew Chung Community College, Hong Kong, China \\ Correspondence: Ivan Chong, 7/F, Kowloon Bay International Trade \& Exhibition Centre, No. 1 Trademart \\ Drive, Kowloon Bay, Hong Kong. Tel: 852-3977-9877. E-mail: ivan.chong@yccc.edu.hk
}

Received: February 25, 2016

Accepted: April 2, 2016 Online Published: April 5, 2016

doi: $10.5539 /$ elt.v9n5p85

URL: http://dx.doi.org/10.5539/elt.v9n5p85

\begin{abstract}
Using pedagogical design capacity $(P D C)$ as the conceptual framework, this single-case study examines how an English teacher in Hong Kong perceives and mobilizes curriculum materials to teach reading comprehension to secondary one students in two stages of implementation. Relying on data collected from semi-structured interviews, lesson observations, and analysis of curriculum materials, the study sought to uncover the underlying teacher knowledge at work when the teacher interacts with the curriculum materials. The findings show that knowledge of curriculum materials, personal practical knowledge, and knowledge of learners play an important role in making teachers more adept at using curriculum materials. Ultimately, the paper concludes with implications both theoretical and practical: The expansion of PDC framework and support to English teachers' use of school-based curriculum materials.
\end{abstract}

Keywords: English language, curriculum materials, pedagogical design capacity, teacher knowledge

\section{Introduction}

There has been a shifting paradigm in curriculum implementation from the fidelity perspective to the mutual adaptation perspective (Fullan \& Pomfret, 1977). Fidelity of implementation, or 'the remote-control approach' (Taylor, 2010, 2012), advocates the importance of planned curriculum over the autonomy of teachers in the process of implementation. On the other hand, proponents of mutual adaptation believe that it is an inescapable reality that teachers modify and adapt the planned curriculum in a bid to cater to the idiosyncrasies in the milieus and students. In light of this, numerous studies have set out to examine the cognitive and pedagogical processes through which teachers adapt the curriculum during enactment (Remillard, 1999, 2000; Remillard \& Bryans, 2004; Taylor, 2010, 2012). A more specific attempt to probe into how teachers adapt curriculum materials was made by Brown (2002), who postulated a competence that teachers exhibit when perceiving and mobilizing resources to craft instructional episodes to achieve their goals - pedagogical design capacity (PDC).

In the area of English Language teaching, while studies examining how teachers use and adapt the curriculum during implementation could be found (Cunningsworth, 1979; Tomlinson \& Masuhara, 2004; McGrath, 2013), not many have attempted to identify and analyze the teacher knowledge conducive to the use of curriculum materials that promotes teaching and learning. Second, although there has been research investigating areas pertaining to curriculum materials development such as evaluation of textbooks (Sampson, 2009; Law \& Nieveen, 2010; Littlejohn, 2011), not much is known about how teachers use in-house curriculum materials and what teachers need to know to implement them effectively. Understanding teacher knowledge is important because how teachers use curriculum materials is greatly contingent on their knowledge base (Charalambous \& Hill, 2012). Upon identifying the underlying knowledge base, in-service teachers could be more readily equipped with such knowledge and their capacity of using curriculum materials could be enhanced.

On the other hand, the exigency of equipping teachers with the necessary knowledge and skills to effectively perceive and mobilize curriculum materials is particularly urgent and relevant to educational contexts where school-based development is encouraged. In Hong Kong, where this study is situated, two centralized educational initiatives: School-based curriculum development (SBCD) and the New Academic Structure (NAS) spawned a plethora of school-based curriculum endeavors (Visiting Panel, 1982; Education Department, 1992), especially those related to materials development. Nevertheless, these endeavors have been deemed short-lived and small-scaled (Yeung, 2010) due to the inadequate capacity given to local teachers, backwash effect of 
examination, and most fundamentally, the lack of skills and knowledge of teachers to design and use in-house curriculum materials (Day, Stobart, Sammons, Kington, \& Gu, 2007). A more recent educational reform in Hong Kong was the NAS implemented in 2009. Amongst the myriads of structural and organizational changes, one that exerted a direct impact on teaching practice would be the introduction of the new curriculum and assessment guides for the core and elective subjects. The English Language Curriculum and Assessment Guide (Secondary 4 - 6) published by the Curriculum Development Institute (2007) presents a curriculum framework which stresses 'flexible and diversified modes of curriculum planning' and 'effective learning, teaching and assessment' (p. 7) in order to expose students to a wide range of interpersonal skills, knowledge, and experience. Despite the provision of detailed schemes of work and resource packages, in-service English teachers still find it hard to use and adapt the often-too-exhaustive resources and curriculum materials provided to suit the needs of their students.

Motivated by the paucity of research intersecting teachers' use of curriculum materials and teacher knowledge, and the practical exigencies that English teachers lack the knowledge to develop and use in-house materials, the study examines how an experienced English teacher in a secondary school used a set of in-house curriculum materials to teach two reading comprehension lessons. By reporting how she used and adapted the materials and analyzing the knowledge base underneath, the study adds new knowledge to existing research on curriculum materials development and use.

\subsection{Pedagogical Design Capacity}

Pedagogical design capacity (PDC) is the capacity enabling teachers to engage in the design activities of teaching through two actions: perceiving and mobilizing existing resources (personal and curricular) to craft instructional episodes (Pea, 1993; Ball \& Cohen, 1999; Brown, 2002; Brown \& Edelson, 2003; Brown, 2009). Referring to Brown and Edelson (2003), perceiving is defined as teachers' act of recognizing and interpreting existing resources, evaluating limitations of classroom setting, and balancing tradeoffs while Remillard (2005) describes it as teachers' ability to recognize and notice potential resources. On the other hand, mobilizing emphasizes teachers' enactment to 'devise strategies' and act on or with the resources (Brown \& Edelson, 2003; Land, 2011). To be more specific to the study, I further categorize perceiving and mobilizing into preactive and interactive (Clark \& Peterson, 1986; Richards, 1996; Borg, 2006; Remillard, 2009). To put into the context of the study, preactive perception refers to teachers' action of recognizing, noticing, interpreting, and evaluating curricular resources and students before instruction while interactive perception denotes all those actions done during lessons. Similarly, teachers' selection and adaptation of curriculum materials before lesson are referred to as preactive mobilization whereas materials selection and adaptation done during lesson are called interactive mobilization.

Conducted in the context of Mathematics education, a number of studies have examined PDC in novice and experienced teachers and how it could be developed. Davis, Beyer, Forbes, and Stevens (2007) examined how PDC could be promoted through teachers' narratives. In a study investigating how four expert teachers mobilize their resources to design teaching episodes to engage students in doing mathematics, Land (2011) found that these expert teachers who possessed high PDC exhibited strong student knowledge. The above studies shed light on the possibility of developing teachers' PDC through in-service and on-going teacher professional development as well as making known one type of knowledge that teachers with high PDC possess i.e. knowledge of learners. These studies confirmed that there exists a bridge between two lines of research: teachers' use of curriculum materials and teacher knowledge. Nonetheless, their focus was on Mathematics education and only one type of teacher knowledge was identified. With English Language Teaching in mind, the present study aims to address this research gap to identify other types of knowledge through analyzing how an experienced English teacher perceived and mobilized in-house curriculum materials.

\subsection{Teacher Knowledge and Its Relevance to Use of Curriculum Materials}

Among the plethora of research setting out to conceptualize teacher knowledge, the seven types of teacher knowledge identified by Shulman (1987): subject-matter knowledge (Shchultz, 2002), pedagogical content knowledge (Hashweh, 2005), curricular knowledge, general pedagogical knowledge, knowledge of learners and their characteristics (Arends, 2004; Rahman, Scaife, Yahya, \& Jalil, 2010), knowledge of educational contexts, and knowledge of educational ends are deemed one of the most comprehensive and representative construct. On the other hand, representing a more individualistic and personal facet of teacher knowledge were the works by Elbaz (1981) and Clandindin and Connelly $(1987,1996)$, which postulated the concept of teachers' personal practical knowledge (PPK). PPK refers to 'a cognitive and affective understanding of the personal knowledge of teachers' (Clandindin et al., 1987, p. 499) and it is defined as 'knowledge, which is experiential, embodied, and 
reconstructed out of the narratives of a teacher's life' (p. 490). Clandindin et al. (1987) believe that through understanding the personal knowledge of teachers, researchers can gain access to a more productive understanding of the meaning of being a teacher and a learner. The introduction of practical knowledge signals a new perspective of understanding teacher knowledge as being more individualistic which can be developed through the interaction between teachers and the educational landscape (Clandinin et al., 1996).

The connection between teachers' use of curriculum materials and their knowledge base is well documented in research. Researchers of teacher knowledge (Brown, 2002, 2009; Kennedy, 2010; Charalambous et al., 2012) posit that teachers' use of curriculum materials is influenced by their knowledge; and by looking into the two resources (curriculum materials and teacher knowledge) in tandem with other contextual factors, it throws light on understanding how teachers can be prepared and equipped with the knowledge to perceive and mobilize curriculum materials effectively.

\section{The Study}

\subsection{Research Questions}

The study addresses the following research questions:

1) How does an experienced English teacher utilize her PDC to perceive and mobilize curriculum materials for teaching reading comprehension preactively and interactively?

2) What kinds of teacher knowledge does she draw upon to perceive and mobilize curriculum materials in her teaching of reading comprehension?

\subsection{Participants and Scope}

The participant of this study, Jessie (pseudonym) is an experienced English Language teacher who has 28 years of experience teaching in local secondary schools in Hong Kong. Prior to working in the present school, she has worked full-time in two private schools as well as served as supply teacher teaching English and History. She studied English, English Literature, and Education in her undergraduate years before receiving her Diploma in Education. She is currently the panel chair of the English Department in the secondary school in which the study was conducted. She teaches Secondary 1, 4, and 6 English Language (Note 1). Jessie was selected to be the participant of this study based on the 'theoretical sampling' method (Strauss \& Corbin, 1998), which seeks participants who can lead to an in-depth understanding of the research topic. Jessie was a very experienced teacher and she was responsible for developing some materials for Secondary 1 and Secondary 4 to facilitate the development of the school-based curriculum. She was invited to participate in the study because her experience would contribute significantly to the understanding of the research questions. Despite its limitation to generalize findings, the study adopted a case study method because it is relevant to the purpose of the study, to explain the complexities of a present phenomenon within a real-life context (how an English teacher uses curriculum materials and why) (Yin, 2009).

This study focuses on one Secondary 1 class that Jessie teaches. This remedial class comprises 16 students. With the number of students less than the regular classes and elite classes (25 students), teachers can devise more suitable teaching strategies and activities to help the less-abled students. Every cycle, the Secondary 1 students have 7 English lessons and each lesson lasts for 55 minutes. The scheme of work for Secondary 1 consists of reading comprehension, grammar teaching, routine writings, listening exercises, and speaking activities. In this study, a reading unit (two 55-minute lessons) for Secondary 1 students was observed and analyzed. Jessie taught a unit (It's Hiking Season!) from Junior Thematic Anthology (Set A) published by Oxford University Press. When teaching the unit, Jessie used the texts (a webpage article and a poem) provided in the textbook alongside some in-house materials, including PowerPoint to teach vocabulary and activity worksheets. These in-house materials were either developed by another teacher teaching the same level or by Jessie herself.

\subsection{Data Collection and Analysis}

Semi-structured interviews, lesson observations and analysis of curriculum materials were methods used for collecting and triangulating data. All interviews, both formal and informal, were conducted in Cantonese as requested by the participant because she felt she was not acquainted with the research topic and that speaking in her first language would allow her to express her ideas more freely. These interviews were translated and transcribed into English by the author. All the transcriptions and translations were sent to the respondents for member check (Merriam, 1988). After the interviews were transcribed, follow-up questions were written on the margins of the transcription for the participant to respond to in order to clarify some ideas or follow up on important ideas. Interview data were analyzed using inductive coding. Categories were identified and later regrouped into larger themes. Two major themes were identified: (1) one pertains to the ways the participant 
perceives and mobilizes curriculum materials before and during instruction; (2) the other is about the implied types of knowledge that the teacher possesses in order to bring about such perceiving and mobilizing.

First, a semi-structured interview was conducted to elicit information concerning the participant's background (e.g. educational background, teaching experience, etc.) and her orientation of using curriculum materials. The interview protocol was derived from Taylor's (2010) study on the interaction between teachers and their textbooks. After the semi-structured interview, the researcher and the participant discussed the research timeline and topic to be observed. It was decided that one unit (It's Hiking Season!) from Junior Thematic Anthology (Set A) would be observed, making up a total of two lessons. This unit was chosen because it was the only unit, during the period of data collection, in which in-house materials were used. Before each lesson observation, the participant completed a lesson overview outlining the basic timeline of the lesson and the lesson materials to be used.

All lessons observed were recorded using a DV camera and field notes were taken focusing on individual teaching activities, how the materials were used, and the structure of the activities. When taking field notes, the lesson observed was broken down into smaller learning tasks. After each lesson, the participant was given a post-observation clarification sheet on which the researcher wrote down some queries concerning the use of curriculum materials, and the participant responded by writing next to each question. Whenever clarification was needed, a short, informal follow-up interview was conducted with the participant.

\section{Findings and Discussion}

3.1 How Does an Experienced English Teacher Utilize Her PDC to Perceive and Mobilize Curriculum Materials for Teaching Reading Comprehension Preactively and Interactively? - RQ1

To facilitate the understanding of how Jessie preactively and interactively perceived the curriculum materials for teaching the reading unit, an overview of the teaching steps suggested by Jessie's colleague and later adapted by Jessie are listed below (Tables 1 and 2):

Table 1. An overview of teaching steps proposed by Jessie's colleague

\begin{tabular}{|c|c|c|c|c|}
\hline $\begin{array}{l}\text { Task } \\
\text { nature }\end{array}$ & $\begin{array}{l}\text { Task } \\
\text { number }\end{array}$ & Description & $\begin{array}{l}\text { Materials } \\
\text { used }\end{array}$ & $\begin{array}{l}\text { Activity } \\
\text { structure }\end{array}$ \\
\hline $\begin{array}{l}\text { Lead-in } \\
\text { Task }\end{array}$ & 1 & $\begin{array}{l}\text { a. Watch a TV announcement by the } \\
\text { government about hiking safety } \\
\text { b. Fill in the blanks in the worksheet }\end{array}$ & $\begin{array}{l}\text { Worksheet } \\
\text { Video clip }\end{array}$ & IW \\
\hline & 2 & $\begin{array}{l}\text { Complete photo captions using the words } \\
\text { provided }\end{array}$ & Worksheet & IW \\
\hline Tasks & 3 & $\begin{array}{l}\text { Introduce important vocabulary from the two } \\
\text { texts }\end{array}$ & PowerPoint & DI-I \\
\hline & 4 & $\begin{array}{l}\text { Complete a leaflet with the information provided } \\
\text { in the article }\end{array}$ & $\begin{array}{l}\text { Worksheet } \\
\text { Textbook }\end{array}$ & IW \\
\hline $\begin{array}{c}\text { Readıng } \\
\text { Tasks }\end{array}$ & 5 & $\begin{array}{l}\text { Choose a photo that reflects the feelings } \\
\text { expressed in the poem }\end{array}$ & $\begin{array}{l}\text { Worksheet } \\
\text { Textbook }\end{array}$ & $\begin{array}{l}\text { IW } \\
\mathrm{P} / \mathrm{S}\end{array}$ \\
\hline
\end{tabular}

\begin{tabular}{ll}
\hline Activity Structure Codes & \\
\hline GW-I = Informal groupwork & CD-T = Class discussion, Teacher-led \\
GW-F = Formal, structured groupwork & CD-S = Class discussion, Student-led \\
IW = Individual seatwork & DI-I = Direct Instruction, Interactive \\
P/S = Presentation/Sharing & DI-N = Direct Instruction, Non-interactive \\
PW = Pair work & L = Logistics \\
\hline
\end{tabular}


Table 2. An overview of teaching steps after Jessie's adaptation (indicated in italics)

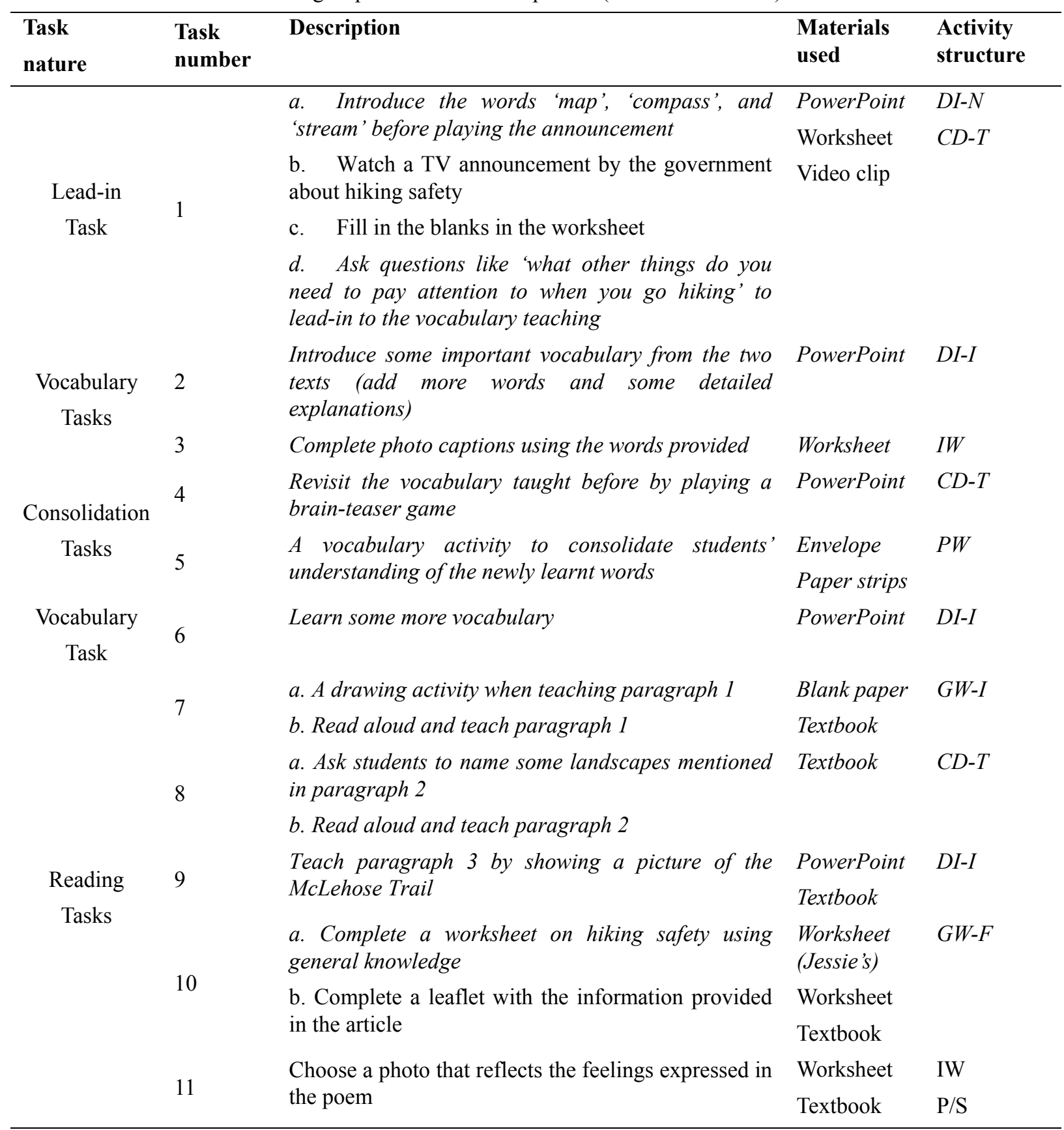

\section{Activity Structure Codes}

GW-I = Informal groupwork

GW-F $=$ Formal, structured groupwork

$\mathrm{IW}=$ Individual seatwork

$\mathrm{P} / \mathrm{S}=$ Presentation/Sharing

$\mathrm{PW}=$ Pair work
CD-T $=$ Class discussion, Teacher-led

$\mathrm{CD}-\mathrm{S}=$ Class discussion, Student-led

DI-I $=$ Direct Instruction, Interactive

DI-N = Direct Instruction, Non-interactive

$\mathrm{L}=$ Logistics 


\subsubsection{Preactive Perception of Curriculum Materials}

\section{Difficulty of tasks}

Jessie paid close attention to the difficulty of each task and evaluated whether her students could handle the tasks. When perceiving the lead-in task (watch a TV announcement and fill in the blanks), Jessie thought the task was suitable for her students because all the key words were provided in the video and students could write down the answers without much difficulty. Nevertheless, when asked about the level of difficulty of the vocabulary tasks, Jessie remarked:

I think it's quite good but I think there are some other words that my class does not understand. Moreover, I will not always teach them every paragraph explicitly and sometimes I want them to read and understand the meaning on their own. They need to understand the words in order to do that. So I will see if the words in the PowerPoint are enough for my students to execute the tasks that I want them to complete.

Jessie concerned whether the difficulty of the words was appropriate to her students and whether the words included were enough. Recalling her experience of teaching some previous reading units, Jessie noted that even after her explanation, her students still had difficulty in understanding the word meaning. In another instance, she mentioned that her students would have difficulty understanding most of the words in the passage. Consequently, Jessie thought that her students might need some more scaffolding with respect to vocabulary because of their low proficiency in English and the foreseeable challenge that her students would face when they worked on the subsequent reading activity. Similar to how she perceived the lead-in task, her emphasis was on the needs of her students.

\section{Task function}

Jessie perceived the function of the lead-in task was to arouse students' interest before she started teaching the vocabulary and the passage in a reading unit. Following this belief, Jessie stressed the importance of the video being new to the students so that they would not feel bored because some of them watched it before. Given the pre-task function of this video task, when asked about how she perceived this activity, she only gave a very short response: 'There is nothing special about this', rendering a relatively minor role to this task. On the contrary, Jessie recognized the importance of the vocabulary tasks as facilitating students' understanding of the texts. She said, 'I will not always teach them every paragraph explicitly and sometimes I want them to read and understand the meaning on their own. They need to understand the words in order to do that'. In light of this, Jessie was rigorous when reading the list of words included in the PowerPoint and expressed the necessity of including more words so that her students would be prepared to comprehend the reading texts.

\section{Task relevance}

Jessie's attention was drawn to how relevant the tasks were to her own teaching objectives. When perceiving the materials of the two reading tasks, Jessie reflected:

When I read the materials, I would see whether students could complete the worksheets without really understanding the passage. If so, I think they are not useful... In some worksheets, I can simply copy all the answers from the text without understanding.

Jessie explicitly said that materials which only required students to copy the information from the text indiscriminately were not useful. She held the belief that reading tasks should check students' understanding of the text by serving as more than an outlet of regurgitated information. Regarding the last task on a poem, Jessie seemed to like the task design because it coincided with her teaching style of using pictures as stimuli to teach word and sentence meaning. She affirmed that pictures could really make students understand what she wanted to teach.

\subsubsection{Preactive Mobilization of Curriculum Materials}

In order to make the curriculum materials more suitable for her students and her teaching style, Jessie mobilized them through: addition and modification (including resequencing and reorganizing the tasks) (Tomlinson et al., 2004).

\section{Mobilizing vocabulary tasks}

The most conspicuous mobilization was noted in the vocabulary tasks in response to their critical function to prepare students for the main reading tasks. Specifically, Jessie mobilized the vocabulary tasks in the following ways: (1) reordered the sequence of vocabulary tasks (Tasks $2 \& 3$ ), (2) included more words in the vocabulary PowerPoint, (3) included more detailed explanations for some words, (4) split the vocabulary PowerPoint into two segments, and (5) added two games for consolidation (Tasks $4 \& 5$ ). One example of Jessie modifying the 
tasks and adding new words could be found in the way she approached the photo captions task (Task 3). Instead of following the planned curriculum and asking her students to complete the photo captions using the words given, Jessie decided to first teach some of the vocabulary items using PowerPoint in order to provide enough scaffolding for the students to complete the task. Concerning the words in the PowerPoint, Jessie added 12 more words in total possibly because of the worry she expressed in the pre-lesson interview:

I will also start the lesson by teaching them some vocabulary. I added some more to the original PowerPoint because I think my students will not understand these. I need to make sure my students understand all the words so they can comprehend the passage.

\section{Mobilizing reading tasks}

When mobilizing the reading tasks provided by her colleague, Jessie exhibited a strong connection with how she perceived the tasks earlier. In accordance with the ways she perceived the tasks, she mobilized the reading tasks by: (1) adding a drawing task (Task 7), (2) adding a class discussion (Task 8), (3) adding a picture to explain a paragraph (Task 9), (4) creating a worksheet eliciting students' general knowledge about hiking (Task 10), and (5) conducting some of the tasks in the format of group-work (Tasks $7 \& 10$ ). Specifically, I would highlight two instances when Jessie created an extra task and modified the format of a task. One time, Jessie mentioned that she would want the reading tasks to help students genuinely understand the text and she preferred using pictures as stimuli to explain the text. Taking these beliefs into account, Jessie designed a drawing task when teaching the first paragraph of the article:

... [I would] invite students to draw a picture about that portion [of the text]. In this way, I could test whether there are any discrepancies between their understanding and the situation described in the paragraph. I can then tell them maybe there should be an area of parkland or another area in the picture or whatsoever. What they draw doesn't need to be exactly the same but at least they have a conception about the paragraph.

Moreover, Jessie showed a propensity of letting students work in groups or holding teacher-led class discussion in order to allow more teacher-student and student-student interactions: 'I adapt the task to allow more room for discussion'. Examples of having group discussion included the drawing task (Task 7) and the general knowledge task (Task 10) while opportunities for whole class discussion were the naming task (Task 8) and the McLehose Trail picture (Task 9).

\subsubsection{Interactive Perception and Mobilization of Curriculum Materials}

When perceiving and mobilizing curriculum materials interactively (i.e. during instruction), Jessie's focus was on students' needs and readiness. This emphasis was evident in Jessie's enactment of Task 1 and Task 4. During the two lessons, Jessie paid close attention to the needs and readiness of her students when considering how to mobilize the curriculum materials. One instance was noted when the fourth task was enacted. Jessie originally planned to revisit the vocabulary taught earlier by having a brainteaser activity with her students. In this task, students had to shout out the words by looking at the pictures on the screen. During enactment, to perceive the needs of her students, Jessie asked whether the students thought it was necessary to revisit the vocabulary; some students responded that they could remember the words. Getting the reassuring response from her students, Jessie decided to abandon this revision task and go directly to the vocabulary activity.

Though not many instances of interactive perception and mobilization of curriculum materials were noted in the two lessons observed, the findings were coherent with what Remillard (2005) described, that teachers adjust the 'task in order to facilitate students' work with them' (p. 226) in the construction arena (interactive stage) by 'reading' their students rather than the curriculum materials. Contrary to the study by Sherin and Drake (2004), which reports that when mobilizing and adapting curriculum materials during instruction, teachers tend to create extra tasks to consolidate students' understanding rather than omit tasks, the participant in this study did not create any extra task in the two lessons observed but omitted one task (Task 4). Despite the different ways of mobilizing curriculum materials (omitting rather than adding), Jessie's consideration when making such deliberation was the same as the one identified in Sherin and Drake's study: students' understanding.

\subsubsection{Alignment between Perception and Mobilization}

It was clear that Jessie had different considerations which influenced her decision-making of how the curriculum materials should be used in the preactive and interactive stages. In the preactive stage, Jessie perceived the curriculum materials chiefly from the perspective of materials design including task appropriateness, level of difficulty, task function, and their role in the whole lesson structure. In the interactive stage, Jessie's main concern was her students: whether her students were prepared to go on to the next task. One important point to note was that Jessie's mobilization of curriculum materials in both the preactive and interactive stages aligned 
with her perception. From the ways Jessie mobilized the materials, it was found that she made informed decisions when mobilizing curriculum materials in both stages. Taken together, Jessie demonstrated high PDC as exemplified in the ways she perceived and mobilized the curriculum materials, and how her mobilization helped in averting the perceived constraints of the materials and her students.

\subsection{What Kinds of Teacher Knowledge Does She Draw Upon to Perceive And Mobilize Curriculum Materials in Her Teaching of Reading Comprehension? - RQ2}

Three types of teacher knowledge were identified in the two stages of curriculum materials use: Knowledge of curriculum materials (KCM), personal practical knowledge (PPK), and knowledge of learners (KLS). While all these knowledge types were evident in both the preactive and interactive stages, the discussion would be mostly on the former because Jessie seldom deviated from her intended teaching plan, rendering little insight into additional knowledge type at work in the latter though she took into consideration the readiness of the students (KLS) when she decided to omit the brain teaser activity.

\subsubsection{Knowledge of Curriculum Materials \& PDC in the Preactive Stage}

As one of the componenets of pedagogical content knowledge (PCK), KCM focuses on teachers' understanding of the progression of skills and knowledge of a topic and the materials available (Grossman, 1990; Huizinga, Handelzalts, Nieveen, \& Voogt, 2014). In the case of Jessie, she seemed to have a very clear understanding of the progressions of skills and knowledge necessary for students to read a passage. In one of the interviews, she delineated her teaching steps in a very succinct way: 'I think a pre-task is important to arouse students' interest, and then I teach the vocabulary, then the passage'.

Responding to this understanding of the progression of knowledge, Jessie mobilized the materials by adding tasks to consolidate her students' understanding of the words in the texts as well as splitting the PowerPoint prepared by her colleague into two segments so that her students did not need to take in too much in one lesson. After understanding the vocabulary in a text, the next skill and knowledge that Jessie thought her students needed was getting the main idea of each paragraph. It was obvious that Jessie deconstructed the article into small portions (i.e. paragraphs) which can be easily handled by her students and designed tasks to help students get the gist of each paragraph. For example, when teaching the second paragraph of the article, Jessie designed a task that required students to locate the landscapes mentioned in the paragraph because the main idea of the paragraph was about the landscapes people would come across when hiking. Lastly, Jessie believed that students' understanding of the text should go beyond the main ideas to relate to students' personal experience. As such, she created a worksheet which elicited students' general knowledge of hiking safety (Task 10) and later invited students to choose a picture to express the emotions in the poem (Task 11) based on their own understanding.

\subsubsection{Personal Practical Knowledge \& PDC in the Preactive Stage}

Jessie's personal practical knowledge (PPK) facilitated her perception of curriculum materials in the preactive stage in a sense that it provided her with a perspective or lens when reading the materials. The two very important personal philosophies or practical principles that characterized Jessie's PPK were: the use of pictures and group-work. In the interviews, Jessie felt very confident to make use of pictures to explain the meaning of words or the main ideas of paragraphs: 'I think pictures can really make students understand what I want to teach'. Although Jessie humbly said that it was a coincidence that she could find a picture that could adequately explain what the paragraph was about, when discussing the ways that she manipulated the pictures to teach word meanings and ideas in the paragraphs, Jessie demonstrated consistently her expertise in making use of pictures to explain word meanings and main ideas effectively in the two lessons observed. One way of mobilizing the materials using her PPK was that Jessie chose pictures which gave her a situation or context to explain a word. For example, Jessie found a picture of a woman doing exercise on a stationary bike to teach the word 'intensive'. She made use of the situation and asked prompting questions to her students: 'When do we need intensive training?' Some students responded by saying 'competition' and 'exam'. Making full use of the situation given by the picture, Jessie was able to explain the meaning of such abstract words.

Another practical principle that Jessie had in her PPK was the use of group-work. When discussing the reason why she wanted to include more group-work in the lesson, she responded by using an example from one of her Secondary 4 English lessons:

The original design is to facilitate students to ask questions concerning certain kinds of summer jobs. I adapt the task to allow more room for discussion. I added something to the worksheet before distributing to the students.

In a bid to facilitate discussions, Jessie adapted existing tasks and created new tasks to provide opportunities for students to share ideas. Amongst the 10 tasks, three of them were conducted in the format of 
group-work/pair-work (Tasks 5, 7, 10) and three in the format of teacher-led, whole-class discussion (Tasks 1, 4, 8).

\subsubsection{Knowledge of Learners \& PDC in the Preactive and Interactive Stages}

Jessie demonstrated her knowledge of learners (KLS), understanding of students' characteristics and how instruction should be adjusted in order to attend to those characteristics (Arends, 2004; Rahman et al., 2010; Rivkin, Hanushek, \& Kain, 2000) by mobilizing the curriculum materials in three ways: (1) strengthening the scaffolding and revision tasks, (2) increasing the amount of input, and (3) simplifying the output. When reading the materials, Jessie pointed out her class was weak and some tasks were quite challenging for her class on many occasions:

I would go through the words in the PowerPoint and maybe add in some more words... Just like this year, my class is quite weak. Even after my explanation, my students still have difficulty in understanding the meaning. Then, I would explain in Cantonese again, so as to make things easier for them to understand.

Sometimes we would ask the students to read the text on their own and complete some tasks, but I find it quite challenging for my class to do so... Because my class is quite weak, I find that even if they can answer the questions, there are some sentences in the passage that they don't really understanding. I would read the passage with them and explain in greater depth.

\section{Preactive stage}

In the preactive stage, Jessie perceived the curriculum materials through the lens of KLS i.e. her students' readiness and ability. From the above transcriptions, it was obvious that Jessie worried that the materials or tasks might be too challenging for her students. This concern was justifiable due to the fact that Jessie's class was a remedial class and the materials were designed to cater for all students in the form. In this way, Jessie mobilized the curriculum materials by adjusting the difficulty of some tasks or creating new tasks to scaffold students' understanding or consolidate newly taught knowledge. For instance, before attempting the task of photo captions (Task 3), Jessie decided to scaffold her students by teaching some vocabulary items using PowerPoint (Task 2). Correspondingly, a brainteaser task (Task 4) and a vocabulary game (Task 5) were created to check students' understanding of newly learnt vocabulary before teaching the article. Second, the level of difficulty of some materials such as the vocabulary PowerPoint was adjusted to suit the ability of her students. 12 extra words were added to the PowerPoint because Jessie thought her students might have difficulties understanding those basic words.

\section{Interactive stage}

In the interactive stage, Jessie's use of curriculum materials was also greatly affected by her KLS. In the lead-in task (Task 1), instead of playing the video once for students to complete the blanks, Jessie played the video one more time because she observed that some students could not get the answers. KLS is an essential component in PDC in both preactive and interactive stages where teachers perceive the needs of students in order to mobilize curriculum materials that can adequately respond to them.

\section{Implications and Conclusion}

With reference to how Jessie perceived and mobilized a set of school-based curriculum materials for teaching reading comprehension (Diagram 1), two implications were drawn regarding the expansion of the PDC framework and how English teachers should be prepared to develop and use school-based curriculum materials. 


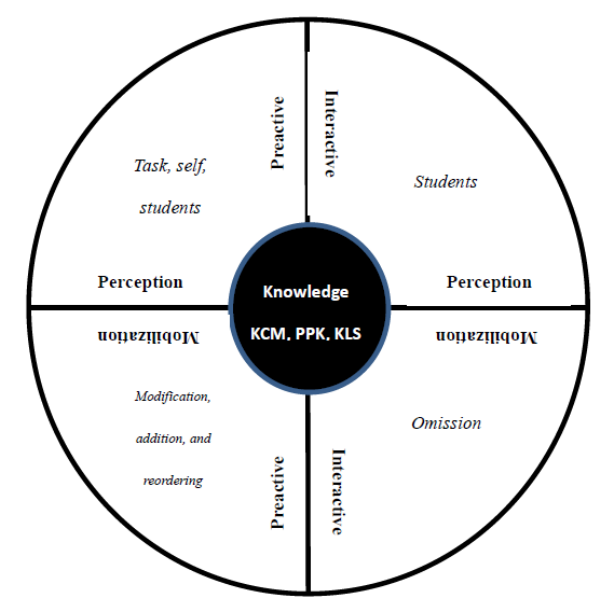

Diagram 1. Diagrammatical representation of Jessie's PDC

\subsection{Theoretical Implications: Expansion of the PDC Framework}

While current research examines ways that teachers use curriculum materials in the context of Mathematics Education using PDC, this study ventures to apply the construct to the area of English Language Teaching. Through analyzing how an experienced English teacher perceived and mobilized in-house materials for teaching reading comprehension in two stages, this study expands the construct of PDC by identifying the underlying teacher knowledge at work which facilitates the development of PDC in teachers. While previous studies on PDC identified that Mathematics teachers with high PDC possess strong KLS, the PDC of Jessie exemplifies two additional types of teacher knowledge: KCM and PPK. In the findings, Jessie paid much attention to the 'constraints' and 'affordances' of the curriculum materials at hand (KCM) (Vygotsky, 1978; Wertsch, 1991, 1998) through the lenses of her own teaching style (PPK) and the needs of her students (KLS). This suggests that teacher knowledge not only operates as discrete variables in affecting a teacher's PDC but also interacts to contribute to her use of curriculum materials. Another theoretical implication is related to PDC in two implementation stages: preactive and interactive. As shown in the findings, Jessie not only mobilized the curriculum materials through modification, addition, and reordering in the preactive stage, she also omitted a task in the interactive stage because her perception changed from resolving mismatches amongst the curriculum materials, her teaching style, and the students' needs to students' readiness. This shows that English teachers' perception and mobilization of curriculum materials is a continuous process that extends from before instruction (preactive) to during instruction (interactive). This sheds important light on the expansion of PDC to take into consideration teachers' ability and action to perceive and mobilize curriculum materials before and during instruction to enable a more holistic understanding of teachers' ability to use curriculum materials.

\subsection{Practical Implication: Support to English Teachers' Use of Curriculum Materials}

In order to empower English teachers to use curriculum materials effectively, support and training should be given to promote teachers' understanding of not only the materials available, but also their teaching style and students' needs. In educational milieus where school-based development of curriculum materials is encouraged, the primary support usually pertains to the development of teachers' KCM only. For example, in Hong Kong where the study was conducted, the Education Bureau provided a plethora of online curriculum materials for schools to use and adapt. There were seminars held to inform teachers of the resources available. Nevertheless, English teachers were still perplexed and frustrated to use the materials provided. One explanation is that there are mismatches between the materials and the teachers' teaching style and the needs of their students. In other words, there is a paucity of support to help English teachers to use curriculum materials in three ways: (1) to reflect on their teaching style, (2) to reflect on the characteristics of their students, and (3) to find out ways to mobilize existing curriculum materials. From the findings, it could be seen that Jessie effectively perceived and mobilized the curriculum materials because she demonstrated her understanding of not only the curriculum materials but also her teaching orientations and students' characteristics. For example, Jessie selected pictures to explain the vocabulary and added some new words to the PowerPoint. This mobilization was informed by her understanding of her teaching style, that is, she is good at teaching words using pictures and her understanding that her students were weak in vocabulary and might need more input. 


\subsection{Limitations of the Study}

The study, however, was not without limitation. The study only focused on how one experienced teacher used curriculum materials in two reading lessons; it did not contrast the possibly unalike ways curriculum materials are used by different teachers. Future research can investigate, in greater depth (by comparing how novice and experienced English teachers use curriculum materials) and over a more extended time span, how different degrees of expertise in the types of teacher knowledge affect the effectiveness of curriculum materials use. Another area for future research would be on expanding the factors which affect a teacher's PDC to include not only teacher knowledge, but also beliefs of teachers and other contextual factors.

\section{References}

Arends, R. I. (2004). Learning to teach (6th ed.). New York: McGraw-Hill.

Ball, D. L., \& Cohen, D. K. (1999). Instruction, capacity, and improvement. Philadelphia, PA: Consortium for Policy Research in Education, University of Pennsylvania.

Ben-Peretz, M. (1990). The teacher-curriculum encounter: Freeing teachers from the tyranny of texts. Albany, NY: State University of New York Press.

Borg, S. (2006). Teacher cognition and language education. London: Continuum.

Brown, M. (2002). Teaching by Design: Understanding the Intersection between Teacher Pracitce and the Design of Curricular Innovations. (Doctor of Philosophy Dissertation), Northwestern University, Evanston, Illinois.

Brown, M. (2009). The teacher-tool relationship. In J. T. Remillard, B. A. Herbel-Eisenmann, \& G. M. Lloyd (Eds.), Mathematics teachers at work: Connecting curriculum materials and classroom instruction (pp. 17-36). New York, NY: Routledge.

Brown, M., \& Edelson, D. C. (2003). Teaching as design: Can we better understand the ways in which teachers use materials so we can better design materials to support their changes in practice? LeTUS Report Series.

Curriculum Development Institute. (2007). English language curriculum and assessment guide (secondary 4 - 6). Hong Kong: Government Printer.

Charalambous, C. Y., \& Hill, H. C. (2012). Teacher knowledge, curriculum materials, and quality of instruction: Unpacking a complex relationship. Journal of Curriculum Studies, 44(4), 443-466. http://dx.doi.org/10.1080/00220272.2011.650215

Clandinin, D. J., \& Connelly, F. M. (1987). Teachers' personal knowledge: What counts as 'personal' in studies of the personal? Journal of Curriculum Studies, 19(6), 487-500. http://dx.doi.org/10.1080/0022027870190602

Clandinin, D. J., \& Connelly, F. M. (1996). Teachers' professional knowledge landscapes: Teacher stories. Stories of teachers. School stories. Stories of schools. Educational Researcher, 25(3), 24-30. http://dx.doi.org/10.3102/0013189X025003024

Clark, C. M., \& Peterson, P. L. (1986). Teachers' thought process. In M. C. Wittrock (Ed.), Handbook of research on teaching (pp. 255-296). New York: Macmillan.

Cunningsworth, A. (1979). Evaluating course materials. In S. Holden (Ed.), Teacher training (pp. 31-33). Oxford: Modern English Publications.

Davis, E. A., Beyer, C., Forbes, C. T., \& Stevens, S. (2007). Promoting pedagogical design capacity through teachers' narratives. Paper presented at the The National Association for Research in Science Teaching, New Orleans.

Day, C., Stobart, G., Sammons, P., Kington, A., \& Gu, Q. (2007). Teachers matter: Connecting lives, work and effectiveness. Berkshire, UK: Open University Press.

Dow, P. (1991). Schoolhouse Politics. Cambridge, MA: Harvard University Press. http://dx.doi.org/10.4159/harvard.9780674330344

Education Department. (1992). SMI manual on school administration. Hong Kong: Government Printer.

Eisner, E. W. (1983). The art and craft of teaching. Educational Leadership, 40(4), 4-13.

Elbaz, F. (1981). The teacher's "practical knowledge": Report of a case study. Curriculum Inquiry, 11(1), 43-71. http://dx.doi.org/10.1080/03626784.1981.11075237 
Fullan, M. G., \& Pomfret, A. (1977). Research on curriculum and instruction implementation. Review of Educational Research, 47(2), 335-397. http://dx.doi.org/10.3102/00346543047002335

Grossman, P. (1990). The making of a teacher: teacher knowledge and teacher education. New York: Teachers College Press.

Hashweh, M. Z. (2005). Teacher pedagogical constructions: A reconfiguration of pedagogical content knowledge. Teachers and Teaching: Theory and Practice, 11(3), 273-292. http://dx.doi.org/10.1080/13450600500105502

Huizinga, T., Handelzalts, A., Nieveen, N., \& Voogt, J. M. (2014). Teacher involvement in curriculum design: Need for support to enhance teachers' design expertise. Journal of Curriculum Studies, 46(1), 33-57. http://dx.doi.org/10.1080/00220272.2013.834077

Kennedy, M. M. (2010). Attribution error and the quest for teaching quality. Educational Researcher, 39(8), 591-598. http://dx.doi.org/10.3102/0013189X10390804

Land, T. J. (2011). Pedagogical design capacity for teaching elementary mathematics: A cross-case analysis of four teachers. Retrieved from http://lib.dr.iastate.edu/cgi/viewcontent.cgi?article=3062\&context=etd

Law, E. H.-f., \& Nieveen, N. (Eds.). (2010). Schools as curriculum agencies: Asian and European perspectives on school-based curriculum development. The Netherlands: Sense Publishers.

Littlejohn, A. (2011). The analysis of language teaching materials: Inside the Trojan Horse. In B. Tomlinson (Ed.), Materials development in language teaching (2nd ed., pp. 179-211). Cambridge, UK: Cambridge University Press.

McGrath, I. (2013). Teaching materials and the roles of EFL/ESL teachers: Practice and theory. London: Bloomsbury Academic.

Merriam, S. B. (1988). Case study research in education. San Francisco: Jossey-Bass.

Pea, R. D. (1993). Practices of distributed intelligence and designs for education. In G. Salomon (Ed.), Distributed cognition (pp. 47-87). New York, NY: Cambridge University Press.

Rahman, F. A., Scaife, J., Yahya, N. A., \& Jalil, H. A. (2010). Knowledge of diverse learners: Implications for the practice of teaching. International Journal of Instruction, 3(2), 83-96.

Remillard, J. T. (1999). Curriculum materials in mathematics education reform: A framework for examining teachers' curriculum development. Curriculum Inquiry, 29(3), 315-342. http://dx.doi.org/10.1111/0362-6784.00130

Remillard, J. T. (2000). Can curriculum materials support teachers' learning? Two fourth-grade teachers' use of a new mathematics text. The Elementary School Journal, 100(4), 331-350. http://dx.doi.org/10.1086/499645

Remillard, J. T. (2005). Examining key concepts in research on teachers' use of mathematics curircula. Review of Educational Research, 75(2), 211-246. http://dx.doi.org/10.3102/00346543075002211

Remillard, J. T., \& Bryans, M. B. (2004). Teachers' orientations towards Mathematics Curriculum Materials: Implications for Teacher Learning. Journal for Research in Mathematics Education, 35(5), 352-388. http://dx.doi.org/10.2307/30034820

Richards, J. C. (1996). Teachers' maxims in language teaching. TESOL Quarterly, 30(2), 281-296. http://dx.doi.org/10.2307/3588144

Rivkin, S. G., Hanushek, E. A., \& Kain, J. F. (2000). Teachers, schools and academic achievement. Retrieved from http://www.utdallas.edu/research/greenctr/papers

Sampson, N. (2009). Teaching materials and the autonomous language teacher: A study of tertiary English teachers in Hong Kong. University of hong Kong. Unpublished EdD thesis.

Shchultz, S. E. (2002). Assessing growth in teaching knowledge. Issues in Teacher Education, 11(1), 49-63.

Sherin, M. G., \& Drake, C. (2004). Identifying patterns in teachers' use of a reform-based elementary mathematics curriculum. Retrieved from http://www.gse.upenn.edu/ janiner/pdf/Sherin.drake.curricmodels.pdf

Shulman, L. (1987). Knowledge and teaching: Foundations of the new reform. Harvard Educational Review, 57(1), 1-23. http://dx.doi.org/10.17763/haer.57.1.j463w79r56455411 
Strauss, A., \& Corbin, J. (1998). Basics of qualitative research. Thousand Oaks, CA: Sage.

Taylor, M. W. (2010). Replacing the "teacher-proof" curriculum with the "curriculum-proof" teachers: Toward a more systematic way for mathematics teachers to interact with their textbooks. (Doctor of Philosophy Dissertation), Stanford University, USA.

Taylor, M. W. (2012). Replacing the 'teacher-proof' curriculum with the 'curriculum-proof' teacher: Toward more effective interactions with mathematics textbooks. Journal of Curriculum Studies, 45(3), 295-321. http://dx.doi.org/10.1080/00220272.2012.710253

Tomlinson, B., \& Masuhara, H. (2004). Developing language course materials. Singapore: SEAMEO RELC.

Visiting Panel. (1982). A perspective on education in Hong Kong: Report by a visiting panel. Hong Kong: Government Printer.

Vygotsky, L. S. (1978). Mind in society: The development of the higher psychological process (A. Kozulin, Trans.). Cambridge, MA: Harvard University Press.

Wertsch, J. V. (1991). Voices of the mind: A sociocultural approach to mediated action. Cambridge, MA: Harvard University Press.

Wertsch, J. V. (1998). Mind as action. New York, NY: Oxford University Press.

Yeung, S. S. Y. (2010). Using school evaluation policy to effect curriculum change? A reflection on the SSE and ESR exercise in Hong Kong. Educational Research Journal, 25(2), 187-209.

Yin, R. K. (2009). Case study research: Design and methods. Thousand Oaks, CA.

\section{Note}

Note 1. The first year of secondary school is known as Form or Secondary One, following six years of primary education. In junior secondary levels (Forms 1-3), students' learning is broader while in senior secondary levels (Forms 4-6), students get to choose their elective subjects and they will sit for a public exam in Form 6 called Hong Kong Diploma of Secondary Education (HKDSE).

\section{Copyrights}

Copyright for this article is retained by the author(s), with first publication rights granted to the journal.

This is an open-access article distributed under the terms and conditions of the Creative Commons Attribution license (http://creativecommons.org/licenses/by/3.0/). 